\title{
Correlation study of venous thromboembolism with SAA, IL-1, and TNF-a levels and gene polymorphisms in Chinese population
}

\author{
Refukaiti Abuduhalike, Juan Sun, Li Zhao, Ailiman Mahemuti \\ Cardiovascular Department, the First Affiliated Hospital of Xinjiang Medical University, Urumqi 830028, China \\ Contributions: (I) Conception and design: A Mahemuti; (II) Administrative support: None; (III) Provision of study materials or patients: None; (IV) \\ Collection and assembly of data: R Abuduhalike, J Sun, L Zhao; (V) Data analysis and interpretation: J Sun, L Zhao; (VI) Manuscript writing: All \\ authors; (VII) Final approval of manuscript: All authors. \\ Correspondence to: Prof. Ailiman Mahemuti. Cardiovascular Department, the First Affiliated Hospital of Xinjiang Medical University, No. 137, \\ Liyushan South Road, New Urban District, Urumqi 830028, China. Email: nayisha2006@hotmail.com.
}

\begin{abstract}
Background: The relationship between inflammation and venous thromboembolism (VTE) has not been fully elucidated.

Methods: Based on our previous studies, we detected the plasma levels of serum amyloid A protein (SAA), interleukin-1 (IL-1), and tumor necrosis factor-a (TNF-a) and their 8 gene polymorphisms by ELISA and a multiplex ligation detection reaction (iMLDR) method in 284 patients with VTE and 268 healthy controls.

Results: Levels of SAA (P=0.032), IL-1 ( $\mathrm{P}=0.045)$, and TNF-a $(\mathrm{P}=0.040)$ were significantly higher in the VTE group than in the control group. Recessive model analysis of the IL-1 rs1800587 variant showed that the risk of VTE in patients with the GG + GA genotype was significantly higher than that in patients with the AA genotype [odds ratio (OR): 4.444; 95\% CI: 1.466-13.470]. Recessive model analysis of the IL-1 rs2234650 polymorphism showed that the risk of VTE in patients with the CC + CT genotype was significantly lower than that in patients with the TT genotype (OR: 0.500; 95\% CI: 0.268-0.934). Multivariate logistic regression analysis showed that the TT genotype at IL-1 rs2234650 (OR: 2.086; 95\% CI: 1.091-3.985) was an independent risk factor for VTE. The AA genotype of IL-1 rs1800587 (OR: 0.226; 95\% CI: 0.074-0.890) was an independent protective factor against VTE.
\end{abstract}

Conclusions: In summary, an intrinsic relationship may exist between inflammatory activation and the occurrence of VTE.

Keywords: Venous thromboembolism (VTE); inflammatory markers; gene polymorphism

Submitted Aug 04, 2019. Accepted for publication Oct 31, 2019.

doi: $10.21037 /$ jtd.2019.11.26

View this article at: http://dx.doi.org/10.21037/jtd.2019.11.26

\section{Introduction}

A large number of evidence-based reports have confirmed a close relationship between inflammatory response and venous thromboembolism (VTE) (1-6). There is a mutually reinforcing pathophysiological relationship between VTE and the inflammatory response. Some reports have confirmed that inflammation may cause the release of tissue factor (TF) and stimulate a coagulation disorder, with thrombosis often activating the inflammatory response (3-9).

As a pro-inflammatory factor, serum amyloid A protein
(SAA) activates the coagulation system (10). Deguchi's study (11) showed that the increase in the plasma SAA level was closely related to VTE. However, there have been reports on the relationship between SAA gene polymorphisms and VTE. Interleukin-1 (IL-1) and tumor necrosis factor-a (TNF-a) are common nonspecific inflammatory markers. Many studies suggest that IL-1 and TNF-a levels and gene polymorphisms may be a risk factor for VTE (12-19). One report, in particular, the Canakinumab Antiinflammatory Thrombosis Outcome Study (CANTOS) trial (20), confirmed that an IL-1-specific antibody could 


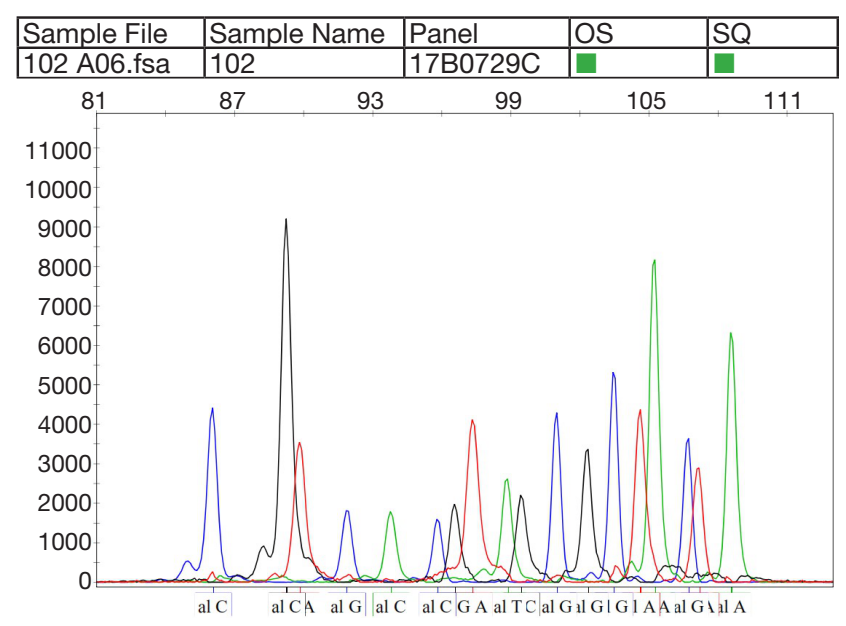

Figure 1 Peak electropherogram of each single-nucleotide polymorphism.

reduce the risk of VTE. However, these studies were conducted in White populations, and there are no reports of studies using Chinese populations. In our previous study, we investigated the relationship between interleukin-6 (IL-6), C-reaction protein (CRP), and methylenetetrahydrofolate reductase (MTHFR) gene polymorphisms with VTE, with the results suggesting that IL-6 gene polymorphisms may be a risk factor for VTE (21-23). On the basis of previous studies, we selected the nonspecific inflammatory markers SAA, IL-1, and TNF-a and their 8 gene polymorphisms to study the relationship between these markers and VTE.

\section{Methods}

\section{Study population}

In this study, 284 patients diagnosed with VTE $(24,25)$ after hospitalization between January 2016 and January 2019 were selected from the VTE specimen bank of the First Affiliated Hospital of Xinjiang Medical University research library as the case group. There were 134 males and 150 females, with an average age of $54.82 \pm 15.47$ years. A total of 268 healthy subjects whose general information, such as age and sex, matched with the case group were selected as the control group. There were 122 males and 146 females, with an average age of $54.21 \pm 15.40$ years.

\section{Biochemical analyses}

Fasting venous blood samples were taken in the morning and centrifuged at a 3000 revolutions per minute for 10 minutes after being placed in a sodium citrate anticoagulant vacutainer tubes. The separated plasma was placed in an Eppendorf tube and stored in a freezer at $-80{ }^{\circ} \mathrm{C}$ for later analysis. After thawing at conventional temperature, the levels of SAA, IL-1, and TNF-a were detected by standard ELISA method.

\section{Genotyping of the inflammatory variants}

The National Center for Biotechnology Information (NCBI) database and previously published literature on candidate variants involved in inflammation were used to select 8 variants related to SAA, IL-1 and TNF-a. Using Shanghai Tianhao Company's iMLDR Multiple Allelic Typing Kit, 8 genotypes were genotyped in 552 samples according to capillary peak electrophoresis by the iMLDR technique (26) (Figure 1).

\section{Statistical analysis}

The statistical software package SPSS 23.0 (International Business Machines Corporation, 2015) was used for statistical analysis. The measurement data satisfying a normal distribution are expressed as the mean \pm standard deviation, and a t-test was used for comparisons between groups. If a normal distribution was not satisfied, measurement data are expressed as the median (P25\% and $\mathrm{P} 75 \%$ ) and a two-sample nonparametric test (MannWhitney $U$ test) was used. A chi-square test was used to compare the categorical variables between groups. The genotype and genotype frequencies of the case and control groups were compared with the predicted value of HardyWeinberg equilibrium by a chi-square test. The odds ratio $(\mathrm{OR})$ was calculated by cross tabulation and logistic regression as an indicator of relative risk. A two-tailed $\mathrm{P}$ value of $<0.05$ was considered indicative of statistical significance.

\section{Results}

History of hypertension $(\mathrm{P}=0.001)$, smoking $(\mathrm{P}=0.010)$, and obesity $(\mathrm{P}=0.002)$ were then identified as risk factors for VTE. Compared with the control group, the levels of SAA $(\mathrm{P}=0.032), \mathrm{IL}-1(\mathrm{P}=0.045)$ and TNF-a $(\mathrm{P}=0.040)$ in the VTE group were significantly higher than those in the control group. There was no significant difference in SAA, IL-1 or TNF-a levels between men and women (Tables 1,2). 
Table 1 Comparison of general clinical information of cases and controls

\begin{tabular}{|c|c|c|c|}
\hline Clinical information & Cases $(n=284)$ & Controls ( $n=268$ ) & $P$ \\
\hline Age, years & $54.82 \pm 15.47$ & $54.21 \pm 15.40$ & 0.595 \\
\hline \multicolumn{4}{|l|}{ Gender, n (\%) } \\
\hline Male & $134(47.183)$ & $122(45.522)$ & 0.696 \\
\hline Female & $150(52.817)$ & $146(54.478)$ & \\
\hline \multicolumn{4}{|l|}{ Hypertension, n (\%) } \\
\hline Yes & $136(47.887)$ & $90(33.582)$ & 0.001 \\
\hline No & $148(52.113)$ & $178(66.418)$ & \\
\hline \multicolumn{4}{|l|}{ Diabetes, n (\%) } \\
\hline Yes & $52(18.310)$ & $33(12.313)$ & 0.051 \\
\hline No & 232 (81.690) & 235 (87.687) & \\
\hline \multicolumn{4}{|l|}{ Smoking, n (\%) } \\
\hline Yes & $129(45.423)$ & $93(34.701)$ & 0.010 \\
\hline No & $155(54.577)$ & 175 (65.299) & \\
\hline \multicolumn{4}{|l|}{ Drinking, n (\%) } \\
\hline Yes & $187(65.845)$ & $170(63.433)$ & 0.553 \\
\hline No & 97 (34.155) & $98(36.567)$ & \\
\hline \multicolumn{4}{|c|}{ Obesity (BMI $\geq 30), n(\%)$} \\
\hline Yes & $125(44.014)$ & $84(31.343)$ & 0.002 \\
\hline No & 159 (55.986) & $184(68.657)$ & \\
\hline
\end{tabular}

BMI, body mass index.

Among the 8 variants selected in our study, only CC genotype were present in the TNF-a rs55933305 variant and only TT genotype were present in the SAA rs2229338 variant. The genotype distribution of each genotype except for SAA rs713332 was consistent with Hardy-Weinberg equilibrium. Because it did not conform to HardyWeinberg equilibrium, follow-up statistical analysis of the SAA rs713332 variant was did not carry out. Because it did not conform to the Hardy-Weinberg equilibrium, a followup statistical analysis of the SAA rs713332 variant was not carried out. The frequencies of the IL-1 rs11800587 GG and GA genotypes were significantly higher in the VTE group than those in the control group (0.662 and 0.324 vs. 0.627 and 0.313 , respectively; $\mathrm{P}=0.016)$. The recessive model analysis showed that the risk of VTE in individuals carrying the GG and GA genotypes was significantly higher than that in individuals carrying the AA genotype (OR: 4.444; 95\% CI: 1.466-13.470). Recessive model analysis of

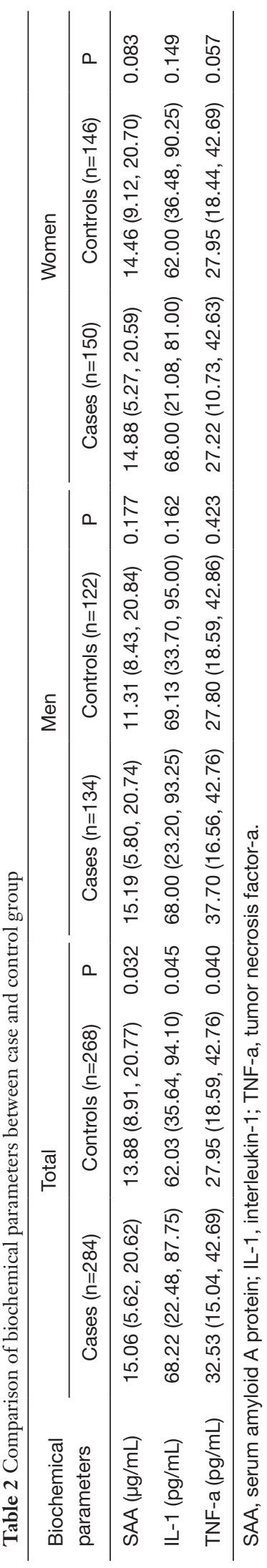


Table 3 Comparison of single nucleotide polymorphisms in inflammatory genes between case and control group

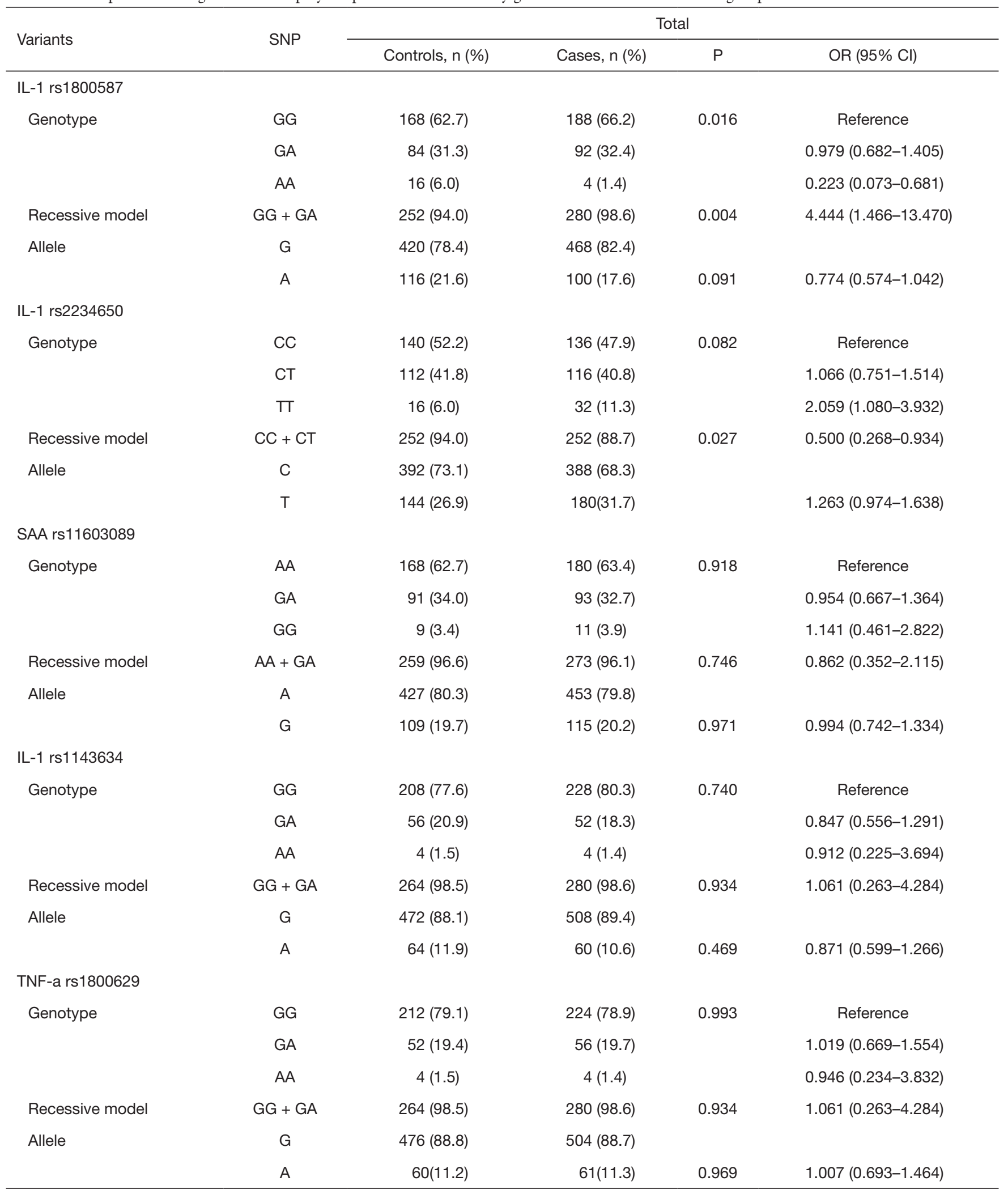

Table 3 (continued) 
Table 3 (continued)

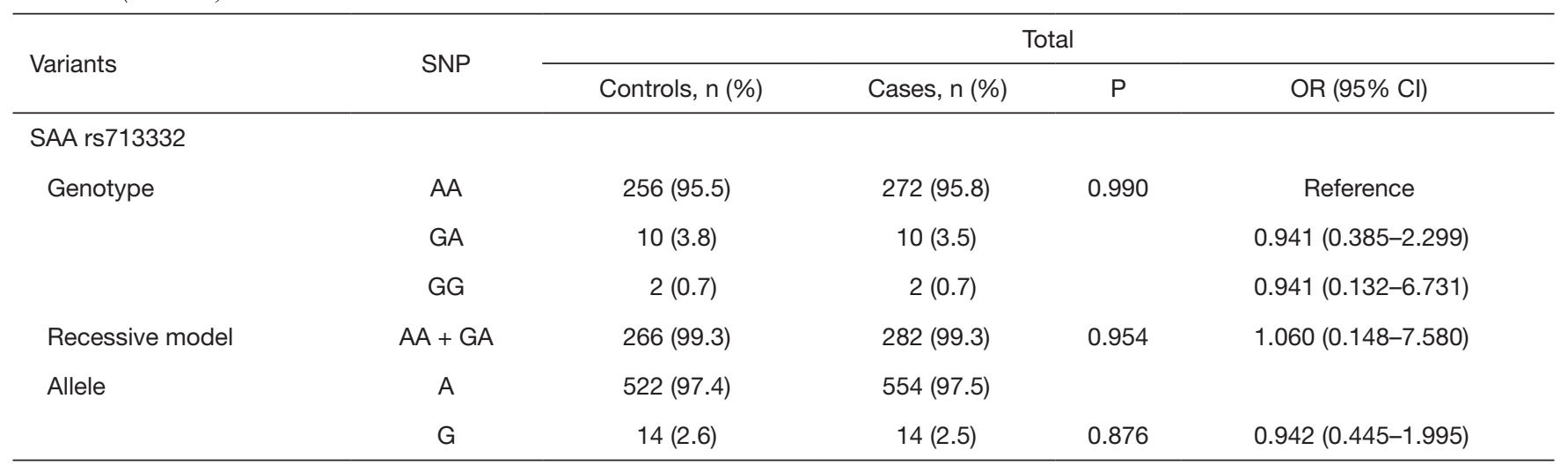

SNP, single nucleotide polymorphism; SAA, serum amyloid A protein; IL-1, interleukin-1; TNF-a, tumor necrosis factor-a.

Table 4 Differences in inflammatory marker levels between each SNP

\begin{tabular}{|c|c|c|c|c|c|c|c|}
\hline Gene & SNP & SAA1 & $\mathrm{P}$ & IL-1a & $\mathrm{P}$ & TNF-a & $P$ \\
\hline \multirow{2}{*}{ IL-1 rs1800587 } & $\mathrm{GA}$ & $10.79(6.13,20.55)$ & & $67.10(24.52,88.00)$ & & $27.80(15.82,42.78)$ & \\
\hline & $\mathrm{AA}$ & $13.60(8.22,18.77)$ & & $71.33(21.57,121.08)$ & & $44.61(30.86,69.03)$ & \\
\hline \multirow[t]{2}{*}{ IL-1 rs1143634 } & GG & $15.06(6.85,20.72)$ & 0.858 & $63.38(27.40,91.00)$ & 0.069 & $29.52(17.00,42.75)$ & 0.981 \\
\hline & AA & $15.16(10.27,20.67)$ & & $94.50(72.00,98.00)$ & & $39.57(9.20,69.03)$ & \\
\hline \multirow[t]{3}{*}{ IL-1 rs2234650 } & $\mathrm{CC}$ & $10.27(6.85,20.73)$ & 0.127 & $62.00(27.40,90.00)$ & 0.068 & $27.98(17.21,42.78)$ & 0.414 \\
\hline & $\mathrm{CT}$ & $15.92(6.63,20.62)$ & & $68.00(26.52,88.00)$ & & $31.74(17.00,42.71)$ & \\
\hline & $\mathrm{TT}$ & $20.24(11.31,20.66)$ & & $73.50(57.64,96.50)$ & & $29.97(11.47,42.41)$ & \\
\hline TNF-a rs1800629 & AA & $20.61(5.37,73.05)$ & & $72.50(21.48,150.25)$ & & $38.92(12.11,157.72)$ & \\
\hline \multirow[t]{3}{*}{ SAA rs11603089 } & $\mathrm{AA}$ & $13.94(6.85,20.69)$ & 0.858 & $63.33(27.40,88.00)$ & 0.580 & $29.42(17.00,42.68)$ & 0.860 \\
\hline & $A G$ & $14.70(7.46,20.75)$ & & $68.99(29.82,94.00)$ & & $30.96(17.38,42.80)$ & \\
\hline & GG & $17.39(5.80,20.48)$ & & $68.99(23.19,86.25)$ & & $30.91(15.06,42.95)$ & \\
\hline
\end{tabular}

SNP, single nucleotide polymorphism; SAA, serum amyloid A protein; IL-1, interleukin-1; TNF-a, tumor necrosis factor-a.

the IL-1 rs2234650 variant showed that the risk of VTE in individuals carrying the CC and CT genotypes was significantly lower than that in individuals carrying the TT genotypes (OR: 0.500; 95\% CI: 0.268-0.934) (Table 3).

Comparison of the SAA, IL-1, and TNF-a levels for each single-nucleotide polymorphism (SNP) revealed no significant difference in these protein levels among the SNPs (Table 4).
Multivariate logistic regression analysis of VTE risk factors after adjusting for risk factors such as hypertension, smoking, body mass index (BMI), and obesity suggested that the TT genotype at the IL-1 rs2234650 variant (OR: 2.086; 95\% CI: 1.091-3.985) was an independent risk factor for VTE. The AA genotype at the IL-1 rs1800587 variant (OR: 0.226 ; 95\% CI: $0.074-0.890)$ was identified as an independent protective factor against VTE (Table 5). 
Table 5 Multivariate factor logistic regression analysis of VTE risk factors

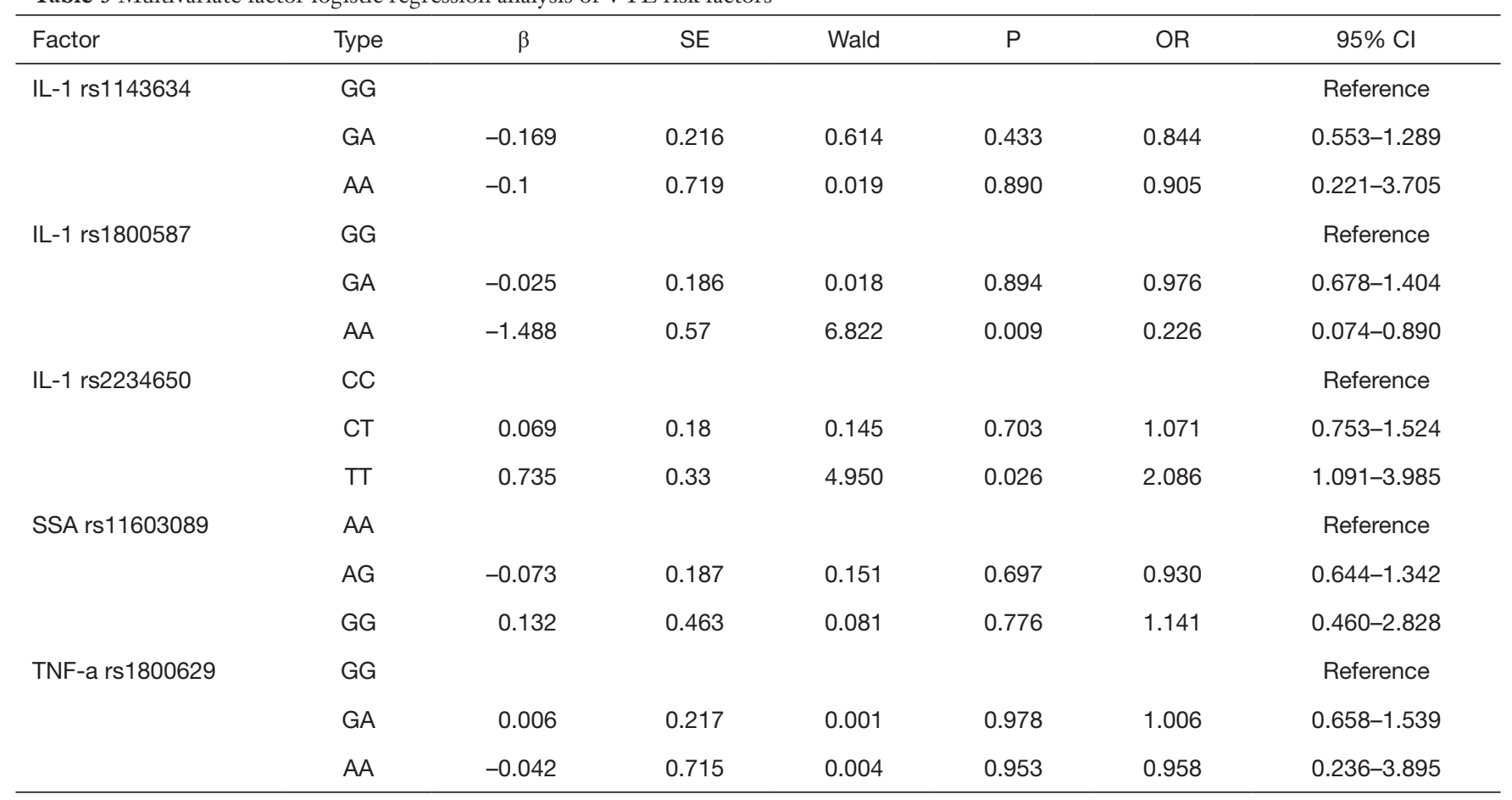

VTE, venous thromboembolism; SAA, serum amyloid A protein; IL-1, interleukin-1; TNF-a, tumor necrosis factor-a; OR, odds ratio.

\section{Discussion}

The relationship between inflammation and VTE has been explored for more than ten years, but no consistent results have been found. SAA is a biomarker that promotes inflammation and coagulation activity. After the activation of inflammation, SAA promotes the secretion of inflammatory cytokines while stimulating the release of TF, and leads to the thrombosis (10). Our study suggests that the level of SAA in the VTE group was significantly higher than that in the control group $(\mathrm{P}=0.032)$, which is consistent with the findings of a study exploring plasma SAA levels in patients with VTE in the United States (11).

IL-1 stimulates the release of TF and promotes the adhesion of leukocytes by inducing endothelial cells to release platelet-derived growth factor (PDGF) and endothelial adhesion factor-1 (ELAM-1), thus increasing blood viscosity and slowing down blood flow $(27,28)$. The CANTOS trial (20) has confirmed that an IL-1 specific antibody can reduce the risk of VTE. Our results suggest that the level of IL-1 in patients with VTE is increased, which is consistent with the results of the Leiden Thrombophilia Study (29). TNF-a activates systemic inflammatory response syndrome by inducing the cytokine network system, leading to endothelial cell necrosis. Our results suggest that the level of TNF-a in the VTE group is increased, which is consistent with the results of the studies of Reitsma (30) and Fox (31).

The genetic risk of VTE is approximately $60 \%$, but most of the specific genetic elements have not yet been revealed (32). Significant differences in the incidence of VTE and gene polymorphisms were found among different regions and races, and the relationship between inflammatory markers and their gene polymorphisms with VTE in the Chinese population is still unclear. Furthermore, there are no reports concerning VTE and SAA gene polymorphisms. Beckers (12) and Zee (13) confirmed the close relationship between IL-1 rs180058 and rs1143634 gene polymorphisms and VTE in Dutch and White females from the United States, respectively. Roselli (16) and Horakova (19) studied Caucasian and Czech populations, respectively, and suggested that TNF-a-308 G gene polymorphism may be associated with the occurrence of VTE. However, the above studies were carried out in a White population from Europe and the United States and did not detect the levels of inflammatory markers. To address this issue, we studied the relationship between 3 inflammatory markers and their 8 gene polymorphisms 
in VTE patients in a Chinese population. The results suggested that the IL-1 rs11800587 GG and GA (OR: 4.444; 95\% CI: $1.466-13.470)$ genotypes are common in patients with VTE, while the IL-1 rs2234650 CC and CT (OR: 0.500; 95\% CI: $0.268-0.934)$ genotypes were common in the control group. Multivariate logistic regression analysis showed that the TT genotype at IL-1 rs2234650 variant (OR: 2.086; 95\% CI: 1.091-3.985) was an independent risk factor for VTE. The AA genotype of the IL-1 rs1800587 variant (OR: 0.226 ; 95\% CI: 0.074-0.890) was identified as an independent protective factor for VTE. The association between VTE and 8 inflammatory gene polymorphisms was revealed in a Chinese population.

Depending on the study population, disease spectrum, and specimen sources, studies on whether the level of inflammatory factors is regulated by their gene polymorphisms have reached different conclusions (33). There was no significant difference in the SAA, IL-1, or TNF-a levels among each SNP in our study, consistent with the research conducted by Brown (33). However, this conclusion is affected by a variety of confounding factors, and gene polymorphism may affect the levels of markers and disease development in a variety of ways; therefore, a large number of clinical studies are needed to truly reveal the correlation between the levels of inflammatory markers and their gene polymorphisms in different populations.

In conclusion, the levels of SAA, IL-1, and TNF-a in patients with VTE were increased, and the activation of inflammation may be related to the occurrence and development of VTE. For the first time, our study revealed a relationship between the levels of multiple inflammatory factors and their gene polymorphisms with VTE in a Chinese population. These findings lay a theoretical foundation for the selection of an appropriate anticoagulant regimen and individualized treatment for Chinese VTE patients based on their inflammatory marker levels and gene polymorphisms. The limitation of our research is that the sample size is small, The limitation of our research is that the sample size is small, and the number of detected markers is less. Large samples and multigene studies need to be carried out to further confirm the relationship between IL-1 and other gene polymorphisms with VTE.

\section{Acknowledgments}

Funding: This work was supported financially by the National Natural Science Fund of China (81560803).

\section{Footnote}

Conflicts of Interest: The authors have no conflicts of interest to declare.

Ethical Statement: The authors are accountable for all aspects of the work in ensuring that questions related to the accuracy or integrity of any part of the work are appropriately investigated and resolved. The Ethics Committee of the First Affiliated Hospital of Xinjiang Medical University reviewed and approved the ethics of this study (No. 20150716-06). Each patient was provided with a description of the study and signed a written informed consent form.

\section{References}

1. Hansson GK. Inflammation and Atherosclerosis: The End of a Controversy. Circulation 2017;136:1875-7.

2. Poredos $P$, Jezovnik MK. The role of inflammation in venous thromboembolism and the link between arterial and venous thrombosis. Int Angiol 2007;26:306-11.

3. Riva N, Donadini MP, Ageno W. Epidemiology and pathophysiology of venous thromboembolism: similarities with atherothrombosis and the role of inflammation. Thromb Haemost 2015;113:1176-83.

4. Bakirci EM, Topcu S, Kalkan K, et al. The role of the nonspecific inflammatory markers in determining the anatomic extent of venous thromboembolism. Clin Appl Thromb Hemost 2015;21:181-5.

5. Vazquez-Garza E, Jerjes-Sanchez C, Navarrete A, et al. Venous thromboembolism: thrombosis, inflammation, and immunothrombosis for clinicians. J Thromb Thrombolysis 2017;44:377-85.

6. Saghazadeh A, Rezaei N. Inflammation as a cause of venous thromboembolism. Crit Rev Oncol Hematol 2016;99:272-85.

7. Wakefield TW, Myers DD, Henke PK. Mechanisms of venous thrombosis and resolution. Arterioscler Thromb Vasc Biol 2008;28:387-91.

8. van Aken BE, den Heijer M, Bos GM, et al. Recurrent venous thrombosis and markers of inflammation. Thromb Haemost 2000;83:536-9.

9. Roumen-Klappe EM, den Heijer M, van Uum SH, et al. Inflammatory response in the acute phase of deep vein thrombosis. J Vasc Surg 2002;35:701-6.

10. Zhao Y, Zhou S, Heng CK. Impact of serum amyloid A on tissue factor and tissue factor pathway inhibitor expression 
and activity in endothelial cells. Arterioscler Thromb Vasc Biol 2007;27:1645-50.

11. Deguchi H, Elias DJ, Navarro S, et al. Elevated serum amyloid $\mathrm{A}$ is associated with venous thromboembolism. Thromb Haemost 2013;109:358-9.

12. Beckers MM, Ruven HJ, Haas FJ, et al. Single nucleotide polymorphisms in inflammation-related genes are associated with venous thromboembolism. Eur J Intern Med 2010;21:289-92.

13. Zee RY, Glynn RJ, Cheng S, et al. An evaluation of candidate genes of inflammation and thrombosis in relation to the risk of venous thromboembolism: The Women's Genome Health Study. Circ Cardiovasc Genet 2009;2:57-62.

14. Fearon WF, Fearon DT. Inflammation and cardiovascular disease: role of the interleukin-1 receptor antagonist. Circulation 2008;117:2577-9.

15. Zee RY, Bubes V, Shrivastava S, et al. Genetic risk factors in recurrent venous thromboembolism: A multilocus, population-based, prospective approach. Clin Chim Acta 2009;402:189-92.

16. Roselli M, Ferroni P, Rolfo C, et al. TNF-alpha gene promoter polymorphisms and risk of venous thromboembolism in gastrointestinal cancer patients undergoing chemotherapy. Ann Oncol 2013;24:2571-5.

17. Gao Q, Zhang $\mathrm{P}$, Wang $\mathrm{W}$, et al. The correlation analysis of tumor necrosis factor-alpha-308G/A polymorphism and venous thromboembolism risk: A meta-analysis. Phlebology 2016;31:625-31.

18. Sarial S, Shokrgozar MA, Amirzargar A, et al. IL-1, IL$1 \mathrm{R}$ and TNFalpha gene polymorphisms in Iranian patients with multiple sclerosis. Iran J Allergy Asthma Immunol 2008;7:37-40.

19. Horakova K, Chylkova A, Kolorz M, et al. Polymorphism G-308A in the promoter of the tumor necrosis factoralpha gene and its association with the risk of venous thromboembolism. Blood Coagul Fibrinolysis 2012;23:316-9.

20. Ridker PM, Everett BM, Thuren T, et al. Antiinflammatory Therapy with Canakinumab for Atherosclerotic Disease. N Engl J Med 2017;377:1119-31.

21. Mahemuti A, Abudureheman K, Aihemaiti X, et al. Association of interleukin-6 and C-reactive protein genetic polymorphisms levels with venous thromboembolism. Chin Med J (Engl) 2012;125:3997-4002.

22. Yadav U, Mahemuti A, Hu X, et al. Single nucleotide polymorphisms in interleukin-6 and their association with venous thromboembolism. Mol Med Rep 2015;11:4664-70.
23. Li Z, Yadav U, Mahemuti A, et al. Association of MTHFR genetic polymorphisms with venous thromboembolism in Uyghur population in Xinjiang, China. Int J Clin Exp Med 2015;8:17703-11.

24. Konstantinides SV, Torbicki A, Agnelli G, et al. 2014 ESC guidelines on the diagnosis and management of acute pulmonary embolism. Eur Heart J 2014;35:3033-69, 69a-69k.

25. Bates SM, Jaeschke R, Stevens SM, et al. Diagnosis of DVT: Antithrombotic Therapy and Prevention of Thrombosis, 9th ed: American College of Chest Physicians Evidence-Based Clinical Practice Guidelines. Chest 2012;141:e351S-e418S.

26. Shi Z, Zhang Q, Chen H, et al. Association of CD40 Gene Polymorphisms with Susceptibility to Neuromyelitis Optica Spectrum Disorders. Mol Neurobiol 2017;54:5236-42.

27. Sun TW, Zhang JY, Li L, et al. Effect atorvastatin on serum tumor necrosis factor alpha and interleukin-1beta following acute pulmonary embolism. Exp Lung Res 2011;37:78-81.

28. Klein NJ, Shennan GI, Heyderman RS, et al. Alteration in glycosaminoglycan metabolism and surface charge on human umbilical vein endothelial cells induced by cytokines, endotoxin and neutrophils. J Cell Sci 1992;102:821-32.

29. Christiansen SC, Naess IA, Cannegieter SC, et al. Inflammatory cytokines as risk factors for a first venous thrombosis: a prospective population-based study. PLoS Med 2006;3:e334.

30. Reitsma PH, Rosendaal FR. Activation of innate immunity in patients with venous thrombosis: the Leiden Thrombophilia Study. J Thromb Haemost 2004;2:619-22.

31. Fox EA, Kahn SR. The relationship between inflammation and venous thrombosis. A systematic review of clinical studies. Thromb Haemost 2005;94:362-5.

32. Larsen TB, Sorensen HT, Skytthe A, et al. Major genetic susceptibility for venous thromboembolism in men: a study of Danish twins. Epidemiology 2003;14:328-32.

33. Brown K, Luddington R, Baglin T. A common polymorphism in the tumour necrosis factor-alpha gene associated with high TNF levels is not a risk factor for venous thromboembolism. Br J Haematol 1998;101:480-2.

Cite this article as: Abuduhalike R, Sun J, Zhao L, Mahemuti A. Correlation study of venous thromboembolism with SAA, IL-1, and TNF-a levels and gene polymorphisms in Chinese population. J Thorac Dis 2019;11(12):5527-5534. doi: 10.21037/ jtd.2019.11.26 